\title{
Difference in Central Corneal Thickness between Applanation Ultrasound and Oculus Wave Light Occulyzer II
}

\author{
Munira Shakir, Ronak Afza Memon, Sahira Wasim, Shakir Zafar
}

Pak J Ophthalmol 2019, Vol. 35, No. 3

See end of article for
authors affiliations
Correspondence to:
Munira Shakir
Department of Ophthalmology,
Liaquat National Hospital
Karachi
Email:
dr_munirasz@yahoo.com

See end of article for authors affiliations

Correspondence to:

Department of Ophthalmology,

Liaquat National Hospital

dr_munirasz@yahoo.com

\begin{abstract}
Purpose: To determine the mean difference of central corneal thickness measurements by using ultrasound Pachymetry and oculus Wave light Occulyzer II.
\end{abstract}

Study Design: Cross-sectional comparative study using non-probability consecutive sampling.

Place and Duration of Study: This study was conducted at Department of Ophthalmology, Liaquat National Hospital Karachi from November 2018 to June 2019.

Material \& Methods: After approval from ethical committee, patients were included in our study on the basis of inclusion \& exclusion criteria. Central corneal thickness measurements were taken by using ultrasound Pachymetry \& oculus Wave light Occulyzer II. All the data was collected by single researcher. The results were plotted, compared \& analyzed. Paired t-test was used for the comparison of quantitative variables.

Results: There were 130 patients included in the study out of which $73(56.2 \%)$ were males and $57(43.8 \%)$ were females. Mean age of these patients was $33.9 \pm 8.9$ years. The mean \pm SD thinnest oculus Wave light Occulyzer II measurement was $538.61 \pm 23.46 \mu \mathrm{m}$ and ranged between 476.0 and $619.0 \mu \mathrm{m}$ whereas the mean thinnest ultrasound Pachymetry measurement was $535.1 \pm$ $21.816 \mu \mathrm{m}$ and ranged between 482 and $601 \mu \mathrm{m}$. There was highly significant correlation of central corneal thickness between both the instruments. $(r=0.96$, $\mathrm{p}<0.001$ ).

Conclusion: There is a high correlation of central corneal thickness between the readings obtained from ultrasound and optical pachymetry machines therefore oculus Wave light Occulyzer II can be used as an alternative technique to ultrasound pachymetry while assessing CCT in clinical settings.

Key Words: Central corneal thickness, Ultrasound Pachymetry, Optical Pachymetry.

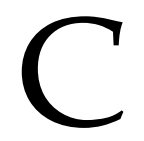
ornea is the main refractive surface of human eye and along with sclera it forms the outer fibrous layer of eyeball. It is transparent and avascular, with normal diameters of about $11-12 \mathrm{~mm}$ \& 9-11 mm horizontal \& vertical respectively ${ }^{1}$.

Corneal thickness is a precise indicator of corneal hydration \& normal functioning of endothelial pump ${ }^{2}$.
CCT has also got an important role in determining the flap thickness along with residual stromal thickness before refractive surgeries ${ }^{3}$. Besides, central corneal thickness, which measures about the central $3 \mathrm{~mm}$ of cornea, is an independent risk factor for the development and progression of glaucoma ${ }^{4}$.

There are various methods for assessing the 
central corneal thickness. The most common is ultrasound pachymetry, which measures CCT by estimating the time difference between echoes of ultrasound waves reflected from anterior and posterior surface of cornea. But this method carries more chances of errors due to misalignment of probe or obliquely placed probe in relation to cornea, lack of light fixation, excessive indentation during procedure \& dryness related problems which include variability in sound transmission ${ }^{5}$. Another method is Corneal topography that uses newer technique known as Scheimpflug imaging, in which a rotating camera is used to photograph corneal cross-sections illuminated by slit beams at different angles (Pentacam). It provides information about anterior segment including iris, angle and cillary body. From these details, the corneal maps give an idea about corneal thickness at different points along with the thinnest point $^{6}$.

The rationale of our study is to find pachymetry techniques with reliable results. Internationally available research also shows wide variability. As central corneal thickness has impact on measuring the intraocular pressure which in turns helps in early detection and management of glaucoma and will help in reducing the overall burden of blindness caused by glaucoma. The purpose of our study is to measure the central corneal thickness using contact (ultrasound) technique \& non-contact (oculus Wave light Occulyzer II) technique and compare the results of two methods in our population.

\section{MATERIAL AND METHODS}

This study was conducted from Nov 2018 to June 2019 at the department of Ophthalmology, Liaquat National Hospital Karachi after approval from ethical committee. The total sample size of 130 patients was calculated using WHO software taking 95\% confidence level. One eye of each of 130 patients, aged between 20-50 years was assessed. Thorough slit lamp examination was performed.

Patients with corneal problems (e.g. scar, keratoconus, keratoglobus), those who were using contact lenses, those who had previous history of refractive or any ocular surgery, those with history of ocular trauma or using ophthalmic drops were not included in this study.

Central corneal thickness was firstly measured on oculus Wave light Occulyzer II (Am Wolfmantel 91058 Erlangen, German). Local anesthetic drops were then instilled and central corneal thickness was measured by ultrasound pachymetry (Sonomed model $300 \mathrm{AP}+$ ) by placing the probe perpendicular to the cornea. Five consecutive readings were taken. All measurements of central corneal thickness were conducted by a single researcher.

Patient's data was compiled and analyzed through Statistical Package for Social Sciences (SPSS) Version 25. Frequency and percentages were computed for qualitative variables such as gender and side of eye.

Mean \pm SD was calculated for age and corneal thickness as quantitative variables. Sample size was calculated by taking Mean \pm SD of the thinnest corneal thickness of $538.7 \pm 0.29 \mu \mathrm{m}^{5}$ with oculus Wave light Occulyzer II using margin of error $(d)=5 \%$. Paired $t$ test was used for the comparison of quantitative variables. $\mathrm{P} \leq 0.05$ was considered as significant.

\section{RESULTS}

There were 130 patients attending ophthalmology department and fulfilling the inclusion criteria. One eye of each patient was measured (65 were right eyes and 65 were left eyes). 73 (56.2\%) were males and 57 $(43.8 \%)$ were females (table 1$)$. Mean age of these patients was $33.9 \pm 8.9$ years. About 78 patients were less than 35 years \& 52 were greater than 35 years (table 1).

In our study, we found that the mean thinnest Pentacam measurement was $538.615 \pm 23.4677 \mu \mathrm{m}$ and ranged between 476.0 and $619.0 \mu \mathrm{m}$, whereas the mean thinnest ultrasound Pachymetry measurement was $535.1 \pm 21.816 \mu \mathrm{m}$ and ranged between 482 and $601 \mu \mathrm{m}$. (Table 2).

Table 1: Descriptive Statistics.

\begin{tabular}{|ll|}
\hline Characteristics & Mean \pm SD \\
\hline Age & $33.93 \pm 8.91$ \\
Age Group & \\
$\leq 35$ years & $27.6 \pm 4.26$ \\
$>35$ years & $43.42 \pm 4.52$ \\
\hline
\end{tabular}

There was highly significant correlation of central corneal thickness between both the instruments. $(\mathrm{r}=$ 0.96, p < 0.001).

According to the results of our study, there were no differences of CCT readings measured by two devices i.e. oculus wave light occulyzer and ultrasound Pachymeter. 
Table 2: Comparison of central corneal thickness between Ultrasound pachymeter and topography.

\begin{tabular}{|lccccc|}
\hline Characteristics & $\mathbf{n}(\%)$ & Ulrrasound Pachymeter & Topography & Correlation $\mathbf{R}$ & P-value \\
\hline $\begin{array}{l}\text { Corneal Thickness } \\
\text { Age }\end{array}$ & $130(100$ & $535.10 \pm 21.8$ & $538.61 \pm 23.4$ & 0.96 & $<0.001^{* *}$ \\
$\quad \quad 35$ years & $78(60$ & $535.29 \pm 22.65$ & $537.59 \pm 23.48$ & 0.97 & $<0.001^{* *}$ \\
$\quad \begin{array}{l}\quad \text { 35 years } \\
\text { Gender }\end{array}$ & $52(40)$ & $534.82 \pm 20.71$ & $537.59 \pm 23.48$ & 0.95 & $0.01^{* *}$ \\
$\quad$ Male & & & & $<0.001^{* *}$ \\
$\quad$ Female & $73(56.2)$ & $532.28 \pm 20.26$ & $536.64 \pm 21.55$ & 0.96 & $0.017^{* *}$ \\
$\begin{array}{l}\text { Eyes } \\
\quad \text { Left }\end{array}$ & $57(43.8)$ & $538.71 \pm 23.34$ & $541.14 \pm 25.68$ & 0.95 & $0.001^{* *}$ \\
$\quad$ Right & $65(50)$ & $536.29 \pm 22.12$ & $539.29 \pm 24.16$ & 0.96 & $<0.001^{* *}$ \\
\hline
\end{tabular}

Paired t-test is applied.

*Significant at $\mathrm{p}$-value $<0.05$

${ }^{* *}$ Insignificant at $\mathrm{p}$-value $>0.05$

\section{DISCUSSION}

Central corneal thickness measurement has a major role in both diagnostic and therapeutic aspects7. Accurate assessment of central corneal thickness is necessary for various concerns such as used preoperatively to prevent corneal ectasia prior to refractive surgery ${ }^{8}$. CCT represents the physiologic function of corneal endothelium ${ }^{9,10}$. It is also useful for diagnosis of some corneal diseases like keratoconus, which is a progressive disease having four stages (1-4), causing thinning and steepening of central cornea11. CCT also helps to decide the management options for Keratoconus, which include corneal crosslinking (CXL) and corneal transplant. CXL basically stabilizes the disease process and requires at least $400-450 \mu \mathrm{m}$ of central corneal thickness. CCT helps in cases of Fuch's dystrophy ${ }^{12}$.

Glaucoma is one of the main causes of blindness these days. Intraocular pressure (IOP) being an important and modifiable risk factor in diagnosis and management of glaucoma has a correlation with central corneal thickness measurement ${ }^{13}$.

There are various methods for CCT measurement, which include both contact and non-contact methods. An ideal method should be accurate, safe, easy, and less time consuming. Ultrasound pachymetry is considered as gold standard for CCT measurement ${ }^{14,15}$. This method requires contact with central cornea. UP has got the disadvantage of using topical anesthetic agents which can affect the thickness. Fixation along with proper position of ultrasound probe has got a major role in CCT measurement. Errors can also occur due to excessive indentation and dryness. On the other hand, pentacam overcomes all the above problems

with UP16. Pentacam uses the rotating Scheimpflug principle, which obtains about 25,000 data points for assessing not only CCT but also corneal curvature and anterior chamber details ${ }^{17}$.

Our study compared the central corneal thickness by applanation ultrasound and oculus Wave light Occulyzer II. Most of the previous literature review showed greater CCT with oculus Wave light Occulyzer II as compared to ultrasound pachymetry (UP). The reason behind this could be the displacement of pre-corneal tear film, which is about 7-30 $\mu \mathrm{m}$. In addition, the compression by ultrasound probe over the epithelium can give thinner CCT measurements by UP18.

Study conducted by Khater et al also compared the mean thinnest corneal thickness with oculus Wave light Occulyzer II $538.7 \pm 29.35 \mu \mathrm{m}$ and with Quantel Pocket II UP $527.6 \pm 28.04 \mu \mathrm{m}$. Their study showed that both devices are highly correlated \& Wave light Occulyzer II can be used as a substitute for UP'19.

Zlatanović et al reported the mean CCT with Occulyzer as $552.94 \mu \mathrm{m} \pm 22.88 \mu \mathrm{m}$ and with ultrasound Pachymetry as $559.46 \pm 26.0 \mu \mathrm{m}$. There were no statistically significant differences among both devices ${ }^{20}$. Piotrowiak et al conducted a study which showed higher value of CCT with ultrasound Pachymetry $(555 \mu \mathrm{m})$ as compared with pentacam (545 $\mu \mathrm{m})^{21}$. Tai et al showed closest agreement for Len StarUP, followed by Len Star-Pentacam and Pentacam$\mathrm{UP}^{22}$.

Limitation of our study was the small sample size and single center for data collection. Multicenter studies are required for further analysis. 


\section{CONCLUSION}

According to the results of our study, there is a high correlation of central corneal thickness found between the readings obtained from both UP and oculus Wave light Occulyzer II. So we concluded that oculus Wave light Occulyzer II can be used as an alternative technique to ultrasound pachymetry, while assessing CCT in clinical settings to decrease the risk of procedure associated problems with UP like epithelial trauma and infection, to decrease the frequent use of topical anesthetic agents, for early detection and management of glaucoma \& in anxious patients as well.

\section{Disclaimer}

None.

\section{Conflict of Interest}

None.

\section{Source of Funding}

None.

\section{REFRENCES}

1. Sridhar MS. Anatomy of cornea and ocular surface. Indian J Ophthalmol. 2018; 66 (2): 190-4.

2. Al-Farhan HM. Measurements of central corneal thickness using two immersion ultrasound techniques and optical technique. J Pak Med Assoc. 2014; 64 (3): 266-70.

3. Sadoughi MM, Einollahi B, Einollahi N, Rezaei J, Roshandel D, Feizi S. Measurement of central corneal thickness using ultrasound pachymetry and Orbscan II in normal eyes. J Ophth Vision Resear. 2015; 10 (1): 4-9.

4. Rashid RF, Farhood QK. Measurement of central corneal thickness by ultrasonic Pachymetry and oculus pentacam in patients with well-controlled glaucoma: hospital-based comparative study. Clinical ophthalmol. 2016; 10: 359-64.

5. Bayhan HA, Bayhan SA, Can İ. Comparison of central corneal thickness measurements with three new optical devices and a standard ultrasonic Pachymetry. Intern J ophthalmol. 2014; 7 (2): 302-8.

6. Grewal DS, Grewal SP. Clinical applications of Scheimpflug imaging in cataract surgery. Saudi J Ophthalmol. 2012; 26 (1): 25-32.

7. Qamar-ul-Islam SM. Comparison of central corneal thickness measurement using non-contact and contact pachymetry devices in normal eyes. Pak J Ophthalmol. 2015; 31 (1): 27-32.

8. Rainer G, Findl O, Petternel V, Kiss B, Drexler W,
Skorpik C, et al. Central corneal thickness measurements with partial coherence interferometry, ultrasound, and the Orbscan system. Ophthalmol. 2004; 111 (5): 875-9.

9. Kocamis O, Kilic R. Repeatability, Reproducibility and Agreement of Central Corneal Thickness Measurements by Two Noncontact Pachymetry Devices. Medical Hypoth Disc Innovat Ophthalmol J. 2019; 8 (1): 34-9.

10. Tam ES, Rootman DS. Comparison of central corneal thickness measurements by specular microscopy, ultrasound pachymetry, and ultrasound biomicroscopy. J Catar Refract Surg. 2003; 29 (6): 1179-84.

11. Amiri MA, Hashemi H, Ramin S, Yekta A, Taheri A, Nabovati $P$, et al. Corneal thickness measurements with Scheimpflug and slit scanning imaging techniques in keratoconus. J Curr Ophthalmol. 2017; 29 (1): 23-7.

12. Lackner B, Schmidinger G, Pieh S, Funovics MA, Skorpik C. Repeatability and reproducibility of central corneal thickness measurement with Pentacam, Orbscan, and ultrasound. Optomet Vision Sci. 2005; 82 (10): 892-9.

13. Yazdani S, Doozandeh A, Haghighat $M$, Akbarian S, Pakravan $\mathbf{M}$, Yaseri $\mathbf{M}$. Intrasubject difference in CCT among POAG versus normal individuals. Optomet Vision Sci. 2015; 92 (8): 879-83.

14. Wong AC, Wong CC, Yuen NS, Hui SP. Co-relational study of central corneal thickness measurements on Hong Kong Chinese using optical coherence tomography, Orbscan and ultrasound pachymetry. Eye, 2002; 16 (6): 715-21.

15. Binnawi KH, Elzubeir H, Osman E, Abdu M, Abdu M. Central corneal thickness measurement using ultrasonic Pachymetry, optical coherence tomography, and TMS-5 topographer. Oman J Ophthalmol. 2019; 12 (1): 15-9.

16. Al-Mezaine HS, Al-Amro SA, Kangave D, Sadaawy A, Wehaib TA, Al-Obeidan S. Comparison between central corneal thickness measurements by oculus pentacam and ultrasonic pachymetry. Internl Ophthalmol. 2008; 28 (5): 333-8.

17. O'Donnell C, Maldonado-Codina C. Agreement and repeatability of central thickness measurement in normal corneas using ultrasound pachymetry and the Oculus Pentacam. Cornea, 2005; 24 (8): 920-4.

18. Amano S, Honda N, Amano Y, Yamagami S, Miyai T, Samejima $\mathbf{T}$, et al. Comparison of central corneal thickness measurements by rotating Scheimpflug camera, ultrasonic pachymetry, and scanning-slit corneal topography. Ophthalmol. 2006; 113 (6): 937-41.

19. Khater MM. Comparative study between oculus Wave light Occulyzer II and Quantel Pocket II ultrasonic Pachymetry in measuring central corneal thickness. Tanta Med J. 2016; 44 (1): 1-3.

20. Zlatanović M, Živković M, Hristov A, Stojković V, Novak S, Zlatanović N, Brzaković M. Central corneal thickness measured by the oculyzer, biograph, and ultrasound pachymetry. Acta Medica Med. 2019; 58 (2): 33-7.

21. Piotrowiak I, Soldanska B, Burduk M, Kaluzny BJ, 
Kaluzny J. Measuring corneal thickness with SOCT, the Scheimpflug system, and ultrasound pachymetry. ISRN Ophthalmol. 2012; 2012: 1-5.

\section{Author's Affiliation}

Dr. Munira Shakir

FCPS, FRCS

Department of Ophthalmology, Liaquat National Hospital, Karachi

Dr. Ronak Afza Memon

MBBS, R4

Department of Ophthalmology, Liaquat National Hospital, Karachi

Dr. Sahira Wasim

MBBS, R4

Department of Ophthalmology, Liaquat National Hospital, Karachi

Dr. Shakir Zafar

FCPS, Department of Ophthalmology, Liaquat National Hospital, Karachi
22. Tai LY, Khaw KW, Ng CM, Subrayan V. Central corneal thickness measurements with different imaging devices and ultrasound pachymetry. Cornea, 2013; 32 (6): 766-71.

\section{Author's Contribution}

Dr. Munira Shakir

Study Design, Manuscript writing, critical analysis.

Dr. Ronak Afza Memon

Researcher, data collection and manuscript writing.

Dr. Sahira Wasim

Data analysis, Manuscript writing.

Dr. Shakir Zafar

Statistical analysis and critical review. 